\title{
3 Research Suare

\section{Impact of COVID-19 infection on short-term outcome in patients referred to stress myocardial perfusion imaging}

\section{Roberta Assante}

University of Naples Federico II: Universita degli Studi di Napoli Federico II

\section{Adriana D'Antonio}

University of Naples Federico II: Universita degli Studi di Napoli Federico II

\section{Teresa Mannarino}

University of Naples Federico II: Universita degli Studi di Napoli Federico II

\section{Valeria Gaudieri}

University of Naples Federico II: Universita degli Studi di Napoli Federico II

\section{Emilia Zampella}

University of Naples Federico II: Universita degli Studi di Napoli Federico II

\section{Ciro Mainolfi}

University of Naples Federico II: Universita degli Studi di Napoli Federico II

Valeria Cantoni

University of Naples Federico II: Universita degli Studi di Napoli Federico II

\section{Roberta Green}

University of Naples Federico II: Universita degli Studi di Napoli Federico II

\section{Elisa Caiazzo}

University of Naples Federico II: Universita degli Studi di Napoli Federico II

\section{Carmela Nappi}

University of Naples Federico II: Universita degli Studi di Napoli Federico II

\section{Emanuele Criscuolo}

University of Naples Federico II: Universita degli Studi di Napoli Federico II

\section{Roberto Bologna}

University of Naples Federico II: Universita degli Studi di Napoli Federico II

Giulia Zumbo

University of Naples Federico II: Universita degli Studi di Napoli Federico II

\section{Mario Petretta}

SDN Foundation: Fondazione SDN

\section{Alberto Cuocolo}

University of Naples Federico II: Universita degli Studi di Napoli Federico II

Wanda Acampa ( $\nabla$ acampa@unina.it ) 
University Federico II https://orcid.org/0000-0003-2187-4076

\section{Research Article}

Keywords: Covid-19, Myocardial perfusion imaging, Prognosis

Posted Date: August 3rd, 2021

DOI: https://doi.org/10.21203/rs.3.rs-761523/v1

License: (c) (i) This work is licensed under a Creative Commons Attribution 4.0 International License. Read Full License

Version of Record: A version of this preprint was published at European Journal of Nuclear Medicine and Molecular Imaging on November 13th, 2021. See the published version at https://doi.org/10.1007/s00259-021-05619-2. 


\section{Abstract \\ Purpose}

We assessed the impact of COVID-19 infection on cardiovascular events in patients with suspected or known coronary artery disease (CAD) referred to stress myocardial perfusion single-photon emission computed tomography (MPS).

\section{Methods}

A total of 950 consecutive patients with suspected or known CAD were submitted by referring physicians to stress MPS for assessment of myocardial ischemia between January 2018 and June 2019. All patients underwent stress-optional rest MPS. Perfusion defects were quantitated as \% of LV myocardium and expressed as total perfusion defect (TPD), representing the defect extent and severity. A TPD $\geq 5 \%$ was considered abnormal.

\section{Results}

During a mean follow-up of 27 months (range 4-38) 31 events occurred. Moreover, 55 (6\%) patients had a COVID-19 infection. The median time from index MPS to COVID-19 infection was 16 months (range 624). At Cox multivariable analysis, abnormal MPS and COVID-19 infection resulted as independent predictors of events. There were no significant differences in annualized event rate in COVID-19 patients with or without abnormal MPS $(p=0.56)$. Differently, in patients without COVID-19 the presence of abnormal MPS was associated with higher event rate $(p<.001)$. Patients with infection compared to those without had a higher event rate in the presence of both normal and abnormal TPD.

\section{Conclusion}

In patients with suspected and known CAD the presence of COVID-19 infection during a short-term followup was associated with a higher rate of cardiovascular events.

\section{Introduction}

The recent outbreak of Coronavirus disease 2019 (COVID-19) has been rapidly spreading on a global scale [1] and it has resulted in considerable morbidity and mortality worldwide. COVID-19 is accompanied by a cluster of flu-like symptoms and life-threatening severe illnesses including acute respiratory distress syndrome, acute kidney injury, myocarditis, and organ failure [2]. The data derived from initial reports and more recent case series has consistently shown a high incidence of cardiac injury, heart failure, circulatory shock and arrhythmias [3]. Therefore, increasing attention is being directed to the relationships between COVID-19 infection and the cardiovascular system regarding two key aspects: 1 ) the role of 
cardiovascular disease as a risk factor for COVID-19 infection and as related unfavorable prognostic element; and cardiovascular complications of COVID-19 infection. Cardiovascular symptoms occur frequently in COVID-19 patients because of systemic inflammatory responses and immune system dysfunction due to disease development. It has been reported that myocardial injury can occur with COVID-19 infection due to a 'cytokine storm' that is stimulated via an imbalanced response and can cause respiratory dysfunction, hypoxemia, shock, or hypotension $[4,5]$. The prevalence of COVID-19 in patients with cardiovascular diseases (CVD) is difficult to estimate due to varying degrees of national surveillance and data collection around the world [6]. Approximately $12 \%$ of COVID-19 patients have been found to have sustained acute heart injuries [7]. Moreover, in a review study approximately $5-25 \%$ of hospitalized COVID-19 cases had elevations in cardiac Troponin, a biomarker of myocardial injury [8]. Patients with acute myocardial injury are older, with a higher prevalence of pre-existing CVD and more likely to require intensive care unit admission [9]. Patients with coronary artery disease (CAD) and COVID19 have higher rates of comorbidities, inpatient mortality and need for renal replacement therapy compared to their non-CAD counterparts. However, CAD was not associated with mortality after adjusting for other covariates, suggesting that other factors may play a predominant role in the increased mortality and poor outcomes in these patients [10]. Evaluating the presence of these chronic conditions is fundamental to mitigate COVID-19 complications and mortality. In a meta-analysis involving 13 studies in patients with COVID-19, cardiac injury was associated with mortality, need for intensive care and severity of disease [11]. However, the effect of COVID-19 infection on the progression and outcome of CVD is still unclear. The aim of the retrospective study was to evaluate the impact of COVID-19 infection on cardiovascular events in patients with suspected or known CAD referred to stress myocardial perfusion single-photon emission computed tomography (MPS).

\section{Methods}

\section{Patients}

A total of 950 consecutive patients with suspected or known CAD were submitted by referring physicians to stress MPS for assessment of myocardial ischemia between January 2018 and June 2019. Patients' clinical history was collected, and cardiac risk factors were assessed before testing. A patient was considered to have known CAD at the time of the MPS based on a provided history of previously diagnosed atherosclerotic coronary disease, history of myocardial infarction (chest pain or equivalent symptom complex, positive cardiac biomarkers, or typical electrocardiographic changes), history of percutaneous coronary intervention, or history of coronary artery bypass grafting. The Ethics Committee of our institution approved the study, and all patients gave informed consent (Protocol Number 110/17).

\section{Study protocol}

All patients underwent stress-optional rest MPS by CZT-SPECT systems (D-SPECT, Spectrum Dynamics, Caesarea, Israel) by $99 \mathrm{~m}-\mathrm{Tc}$ sestamibi physical exercise or dipyridamole stress test, according to the recommendations of the European Association of Nuclear Medicine [12, 13]. In all patients, beta-blocking 
medications and calcium antagonists were withheld for 48 hours and long-acting nitrates for 12 hours before testing. For patient undergoing exercise test, symptom-limited treadmill standardized protocols were performed, with monitoring of heart rate and rhythm, blood pressure, and ECG. Test endpoints were achievement of $85 \%$ maximal predicted heart rate, horizontal or down-sloping ST-segment depression $>2$ $\mathrm{mm}$, ST-segment elevation $>1 \mathrm{~mm}$, moderate to severe angina, systolic blood pressure decrease $>20 \mathrm{~mm}$ $\mathrm{Hg}$, blood pressure $>230 / 120 \mathrm{mmHg}$, dizziness, or clinically important cardiac arrhythmia. For dipyridamole stress test, patients were instructed not to consume products containing caffeine for 24 hours before the test. Dipyridamole was infused at dose of $0.142 \mathrm{mg} / \mathrm{kg}$ per min intravenous over 4 minutes. A dose of $100 \mathrm{mg}$ of aminophylline was administered intravenously in the event of chest pain or other symptoms, or after significant ST depression. At peak exercise, or 4 minutes after completion of dipyridamole infusion, a bolus of $370 \mathrm{MBq}$ of $99 \mathrm{mTc}$-sestamibi was injected intravenously. For both types of stress, heart rate, blood pressure, and 12-lead ECG data were recorded at rest, at the end of each stress stage, at peak stress and in the delay phases at rest. Maximal degree of ST-segment changes at 80 ms after the J-point of the ECG was measured and assessed as horizontal, down-sloping, or up-sloping. Horizontal or downsloping ST-segment depression $\geq 0.1 \mathrm{mV}$, persisting for at least 0.06 to 0.08 seconds after the J-point in one or more ECG lead, were considered diagnostic for ischemia, whereas upsloping ST depressions $\geq 1.0 \mathrm{~mm}$ were considered nondiagnostic. All ST depression $<1.0 \mathrm{~mm}$ additional from baseline was defined as negative. Recordings were obtained using 9 pixilated CZT crystal detector columns mounted vertically spanning a $90^{\circ}$ geometry. Each of the columns consists of 1,024 (16 $\left.9 \cdot 94\right)$ 5 -mm thick CZT crystal elements $(2.46 \cdot 9 \cdot 2.46 \mathrm{~mm})$. Square hole tungsten collimators are fitted to each of the detectors, which are shorter than conventional low-energy, high-resolution collimators, yielding significantly better geometric speed [14]. Data were acquired focusing on the heart by the detectors rotating in synchrony and saved in list mode. Images were obtained with the patient in a semi recumbent position. A 10-s pre-scan acquisition was performed to identify the location of the heart and to set the angle limits of scanning for each detector (region of interest-centric scanning). Using the myocardial count rate from the pre-scan acquisition, the time per projection was set to target the recording of 1000 myocardial kcounts; the duration of the scans was less than 10 minutes for stress and 4 minutes for rest. Summed and gated projections were reconstructed with an iterative maximum likelihood expectation maximization algorithm using 7 and 4 iterations, respectively [15]. An automated software program (esoft 2.5, QGS/QPS, Cedars-Sinai Medical Center, Los Angeles, CA) was used to calculate left ventricular (LV) volumes, ejection fraction, wall motion, wall thickening, and the scores incorporating both the extent and severity of perfusion defects, using standardized segmentation of 17 myocardial regions $[16,17]$. The total perfusion defect (TPD) of the stress images was also generated, representing the defect extent and severity and expressed as a percentage of the LV myocardium. A TPD $\geq 5 \%$ was considered abnormal [18].

\section{Outcome}

Patient follow-up was obtained by use of a questionnaire that was assessed by a phone call to the patients, general practitioners or cardiologists and by review of hospital or physicians' records by individuals blinded to the patient's test results. The follow-up questionary included all possible data 
linked to COVID-19 infection: time and duration of the infection, symptoms, hospitalization and related course. Moreover, outcome was composite end-point of cardiac death, nonfatal myocardial infarction, or unstable angina requiring coronary revascularization, whichever occurred first. The cause of death was confirmed by review of death certificate, hospital chart, or physician's records. Death was of cardiac origin if the primary cause was defined as acute myocardial infarction, congestive heart failure, valvular heart disease, sudden cardiac death, or cardiac interventional/ surgical procedure related. Myocardial infarction was defined when $>2$ of the following 3 criteria was met: chest pain or equivalent symptom complex, positive cardiac biomarkers, or typical electrocardiographic changes [19]. The date of the last examination or consultation was used to determine the length of follow-up.

\section{Statistical analysis}

Continuous data are expressed as mean \pm standard deviation and categorical data as percentage. A student two-sample t-test and chi-square test were used to compare the differences in continuous and categorical variables, respectively. A $p<0.05$ (two-sided) was considered statistically significant. Annualized event rates (AER), expressed as \% person-years, were calculated as the cumulative number of events divided by person-time. This latter is an estimate of the actual time-at risk that all persons contribute to the study, i.e., the sum of each individual follow-up period. Because patients shifted from the no COVID-19 to the COVID-19 group during follow-up, unadjusted event free survival functions were estimated using the method proposed by Simon-Makuch [20], a modification of Kaplan-Meier analysis, and compared using the Mantel-Byar test [21]. In this context, COVID-19 is treated as a binary nonreversible time-dependent covariate that starts at 0 (no COVID-19) and may switch to 1 (COVID-19) at some time point. Thus, the study cohorts are continually updated as follows: for the time prior to COVID19 infection, the patient contributes to the no COVID-19 cohort, but for the time after COVID-19 infection, the patient contributes to the COVID-19 cohort. The start time $\left(t_{0}\right)$ for the no COVID-19 group is the beginning of follow-up (index MPS), while for the COVID group $t_{0}$ is the date of COVID-19 infection after index MPS. The impact of COVID on event-free survival was evaluated with the extended Cox regression model. To consider differences in the time from index MPS to COVID-19, COVID-19 was treated as a binary non-reversible time-dependent covariate. Thus, COVID-19 patients were members of the no COVID19 group until the day of infection. At that point, they were crossed over to the COVID-19 group. This means that patients contribute to the hazard estimate of the no COVID-19 group up to the infection time, when they start to contribute to the hazard estimate of the COVID-19 group. Statistical analysis was performed with Stata 16 software (StataCorp, College Station, Texas USA).

\section{Results}

\section{Patient characteristics and outcome}

Follow-up data were not available in $73(8 \%)$ of the 950 patients, leaving 877 subjects for the analysis. Over a median follow-up of 27 months (range 4-38) 31 cardiac events occurred (3.5\% cumulative event 
rate) and 6 patients died for COVID-19 infection. Cardiac events were cardiac death in 9 (29\%), nonfatal myocardial infarction in $5(16 \%)$ and revascularization procedures in $17(55 \%)$ patients.

Patient's characteristics and imaging findings according to the occurrence of cardiac events are reported in Table 1. Patients with events showed a higher prevalence of smoking history and known CAD. A higher prevalence of abnormal MPS was also observed in patients with events. During the follow-up, $55(6 \%)$ patients presented a COVID-19 infection and 822 (94\%) did not. The median time from index MPS to COVID-19 infection was 16 months (range 6-24). Clinical characteristics and imaging findings according to the occurrence of COVID-19 infection are described in Table 2. As shown, patients with COVID-19 had lower mean age and a higher prevalence of atypical angina as compared to patients without COVID-19. All the others clinical characteristics were comparable between the two groups. Moreover, the prevalence of abnormal MPS was similar in patients with and without COVID-19. The cumulative event rate was $14 \%$ in patients with COVID-19 and $2.8 \%$ in those without $(p<0.001)$.

Table 1

Clinical characteristics and imaging findings according to cardiac events

\begin{tabular}{|lllll|}
\hline & $\begin{array}{l}\text { All patients } \\
(n=877)\end{array}$ & $\begin{array}{l}\text { Event } \\
(n=31)\end{array}$ & $\begin{array}{l}\text { No Event } \\
(n=844)\end{array}$ & $p$ value \\
\hline Age (years) & $64 \pm 10$ & $63 \pm 9$ & $64 \pm 10$ & 0.67 \\
\hline Male gender, $n(\%)$ & $587(67)$ & $24(76)$ & $563(66)$ & 0.20 \\
\hline Body mass index $\left(\mathrm{kg} / \mathrm{m}^{2}\right)$ & $28 \pm 5$ & $28 \pm 4$ & $28 \pm 5$ & 0.82 \\
\hline Diabetes, $n(\%)$ & $274(31)$ & $13(48)$ & $261(30)$ & 0.19 \\
\hline Hypertension, $n(\%)$ & $753(86)$ & $30(97)$ & $723(85)$ & 0.07 \\
\hline Dyslipidemia, $n(\%)$ & $591(67)$ & $23(69)$ & $568(67)$ & 0.41 \\
\hline Smoking history, $n(\%)$ & $529(60)$ & $26(76)$ & $503(60)$ & $<0.01$ \\
\hline Family history of CAD, $n(\%)$ & $482(55)$ & $21(64)$ & $461(55)$ & 0.14 \\
\hline Angina symptom, $n(\%)$ & $302(34)$ & $12(39)$ & $290(34)$ & 0.61 \\
\hline Known CAD, $n(\%)$ & $379(43)$ & $21(67)$ & $358(42)$ & $<0.01$ \\
\hline Abnormal MPS, $n(\%)$ & $288(33)$ & $18(61)$ & $270(32)$ & $<0.005$ \\
\hline Pharmacological stress test, $n(\%)$ & $484(55)$ & $20(61)$ & $464(55)$ & 0.52 \\
\hline CoVID-19, $n(\%)$ & $55(6)$ & $8(24)$ & $47(5)$ & $<0.001$ \\
\hline Values are expressed as mean value \pm standard deviation or as number (percentage) & \\
\hline $\begin{array}{l}\text { CAD coronary artery disease, MPS myocardial perfusion single-photon emission computed } \\
\text { tomography }\end{array}$ & & & \\
\hline
\end{tabular}


Table 2

Clinical characteristics and imaging findings according to COVID-19 infection

\begin{tabular}{|lllll|}
\hline & $\begin{array}{l}\text { All patients } \\
(n=877)\end{array}$ & $\begin{array}{l}\text { COVID-19 } \\
(n=55)\end{array}$ & $\begin{array}{l}\text { No COVID-19 } \\
(\boldsymbol{n}=822)\end{array}$ & p value \\
\hline Age (years) & $64 \pm 10$ & $61 \pm 10$ & $64 \pm 10$ & $<0.01$ \\
\hline Male gender, $n(\%)$ & $587(67)$ & $37(67)$ & $550(67)$ & 0.95 \\
\hline Body mass index $\left(\mathrm{kg} / \mathrm{m}^{2}\right)$ & $28 \pm 5$ & $29 \pm 5$ & $28 \pm 5$ & 0.74 \\
\hline Diabetes, $n(\%)$ & $274(31)$ & $18(35)$ & $256(31)$ & 0.80 \\
\hline Hypertension, $n(\%)$ & $753(86)$ & $49(88)$ & $704(86)$ & 0.47 \\
\hline Dyslipidemia, $n(\%)$ & $591(67)$ & $42(75)$ & $549(67)$ & 0.14 \\
\hline Smoking history, $n(\%)$ & $529(60)$ & $32(58)$ & $497(60)$ & 0.07 \\
\hline Family history of CAD, $n(\%)$ & $482(55)$ & $37(65)$ & $445(54)$ & 0.06 \\
\hline Angina symptom, $n(\%)$ & $302(34)$ & $26(48)$ & $276(33)$ & $<0.05$ \\
\hline Known CAD, $n(\%)$ & $379(43)$ & $21(38)$ & $358(43)$ & 0.43 \\
\hline Abnormal MPS, $n(\%)$ & $288(33)$ & $16(29)$ & $272(33)$ & 0.54 \\
\hline Values are expressed as mean value \pm standard deviation or as number (percentage) & \\
\hline $\begin{array}{l}\text { CAD coronary artery disease, MPS myocardial perfusion single-photon emission computed } \\
\text { tomography }\end{array}$ & & & \\
\hline
\end{tabular}

\section{Predictors of events}

The results of Cox univariable and multivariable analysis for prediction of cardiac events are reported in Table 3. At multivariable analysis, only abnormal MPS and COVID-19 infection were significant predictors of events. Event free survival was better in patients without than in those with COVID-19 $(p<0.001)$ (Fig. 1). The AER according to COVID-19 infection and MPS are depicted in Fig. 2. Patients with infection compared to those without had a higher event rate in the presence of both normal and abnormal TPD. 
Table 3

Univariable and multivariable predictors of cardiac events

\begin{tabular}{|lllll|}
\hline & Univariable analysis & & Multivariable analysis & \\
\hline Age & Hazard ratio $(95 \% \mathrm{Cl})$ & $p$ value & Hazard ratio $(95 \% \mathrm{Cl})$ & $p$ value \\
\hline Male gender & $0.994(0.961-1.028)$ & 0.71 & & \\
\hline Body mass index & $0.590(0.254-1.368)$ & 0.21 & & \\
\hline Diabetes & $0.992(0.926-1.062)$ & 0.81 & & \\
\hline Hypertension & $1.608(0.788-3.282)$ & 0.19 & & \\
\hline Dyslipidemia & $5.070(0.691-37.179)$ & 0.11 & & \\
\hline Smoking history & $1.430(0.639-3.197)$ & 0.38 & & \\
\hline Family history of CAD & $3.132(1.186-8.270)$ & $<.05$ & & \\
\hline Known CAD & $1.754(0.826-3.726)$ & 0.14 & & \\
\hline Abnormal MPS & $1.812(0.783-4.190)$ & 0.16 & & \\
\hline CoviD-19 & $2.809(1.376-5.733)$ & $<0.005$ & $2.201(1.030-4.704)$ & $<.05$ \\
\hline $\begin{array}{l}\text { Cl confidence interval, CAD coronary artery disease, MPS myocardial perfusion single-photon } \\
\text { emission computed tomography }\end{array}$ & & & \\
\hline
\end{tabular}

There were no significant differences in AER in COVID-19 patients with or without abnormal MPS ( $p=$ 0.56). On the contrary, in patients without COVID-19 the presence of abnormal MPS was associated with a higher event rate $(p<0.001)$. The event-free survival curves according to COVID-19 and MPS results are reported in Fig. 3. Patients with COVID-19 and abnormal MPS had the worst outcome with a lower eventfree survival as compared to patients without COVID-19 with both normal and abnormal MPS $(p<0.001)$. Yet, the event-free survival was similar in patients with COVID-19 and normal MPS and those with COVID19 and abnormal MPS $(p=0.48)$. There was no difference in event free-survival between patients without COVID 19 and with abnormal MPS and patients with COVID-19 but normal MPS. The best outcome was observed in no COVID-19 patients and normal MPS.

\section{Discussion}

The present study demonstrated that patients referred to stress MPS for evaluation of suspected or known CAD, who presented COVID-19 infection during follow-up had a higher incidence of cardiac events compared to patients without subsequent COVID-19 infection. In particular, COVID-19 infection and abnormal MPS were both independent predictors of cardiac events at follow-up. 
After its insurgence, COVID infection has spread to more than 200 countries, and mortality of the critical patients has been reported to be as high as 50\% [22]. Previous studies demonstrated that patients with COVID-19 infection and other comorbidities were more frequently affected by a severe COVID-19 disease with a higher rate of mortality [23]. Therefore, increasing attention is being directed to analyze the impact of underlying diseases on the prognosis of COVID-19 [24-26]. In particular, cardiac disease represents the most common comorbidity in patients with COVID-19 and it has been demonstrated that CVD can be regarded as a strong risk factor for rapid progression and poor prognosis of COVID-19 [27].

In a retrospective study of 138 patients from the University of Wuhan, patients who met the need for admission to the intensive care unit were significantly older and had underlying comorbidities more frequently, such as hypertension, diabetes mellitus and known CAD [9]. On the other hand, it is plausible that also the presence of COVID-19 infection may contribute to accelerate the cardiovascular disease progression. The basis of myocardial damage from COVID-19 exists direct damage to myocardiocytes, systemic inflammation, myocardial interstitial fibrosis, exaggerated T-cell Helper Type 1 and 2 activation, coronary plaque destabilization and hypoxia [28]. In our study population the presence of COVID-19 infection and abnormal MPS was associated with the worst prognosis in a follow-up of about two years. Patients with normal MPS and without COVID-19 disease showed the best prognosis. Interestingly, there were no significant difference in outcome between patients with COVID-19 and normal or abnormal MPS. The presence of COVID-19 infection in patients with suspected or known CAD is seems to be decisive in defining the risk of cardiac event. It may be possible that the presence of COVID-19 could be responsible of cardiac disease progression and poor outcome independently of others cardiac risk factors and the presence of abnormal perfusion.

It is well known that Coronaviruses can bind to some metal peptidases such as ACE2, which is present in the epithelial cells of the pulmonary alveoli, epithelial cells of the small intestine, arterial and venous endothelial cells and smooth muscle cells [29]. The variety of expression of ACE2 suggests the correlation between SARS-COVID-2 and extra-pulmonary manifestations, in particular cardiac involvement. COVID-19 through its Spike protein binds strongly to ACE2 receptors and after entering cells, determines a down-regulation of the expression of ACE2, for which the enzyme is no longer able to perform his role. Sars-COVID 2 is therefore able to down regulate the ACE2 pathways at the myocardial and pulmonary level, mediating myocardial inflammation, pulmonary edema and acute respiratory failure [30]. Adult patients affected by CVD, arterial hypertension, diabetes, and/or chronic obstructive pulmonary disease show worse clinical outcome following contraction of the viral illness with fatality rate attaining $10.5 \%$ [31]. In addition, the cytokine storm associated to virus infection as an expression of an exaggerated response of the host's immune system, is highly detrimental to the heart. Cardiac complications associated with viral pneumonia include malignant arrhythmias, myocardial infarction, and heart failure [31]. Myocardial damage during COVID-19 can be asymptomatic and therefore can only be evaluated with laboratory markers, or it can be clinically evident. A recent meta-analysis reports how the evolution of COVID-19 disease can exacerbate a pre-existing ventricular dysfunction or predispose to a new cardiomyopathy [32]. Therefore, the presence of underlying cardiovascular comorbidities in patients with COVID-19 is associated with high mortality. However, on the other hand COVID-19 can cause 
cardiovascular disorders, including myocardial injury, arrhythmias, acute coronary syndrome and venous thromboembolism. Our preliminary results involved a limited number of patients in a short-term followup. Probably an analysis in a larger study population followed for more time could help to better elucidate the relationship between COVID-19 infection and cardiovascular disease and to evaluate the correlation between infection and poor outcome. Moreover, it has been demonstrated that COVID-19 induced an endothelial cell dysfunction by an excessive generation of thrombin and a shutdown of fibrinolysis, which indicate a state of hyper-coagulability [33]. Therefore, investigations on microvascular and endothelial damage can play a fundamental role in explaining the pathophysiological mechanisms, the clinical course and for the development of new treatments, as well as to reduce the number of those who will need intensive care units.

\section{Conclusions}

In our series of patients with suspected and known CAD undergoing to stress MPS, the presence of COVID-19 infection was associated with a significantly higher rate of cardiovascular events during a short-term follow-up, independently of others cardiovascular risk factors. COVID-19 and abnormal MPS were both associated with an increased risk of cardiac events in these patients. A possible interaction of COVID-19 infection on cardiovascular system may have a role in a poor outcome in patients with suspected or known CAD.

\section{Declarations}

Author contributions R.A, M.P., A.C., and W.A. conceptualized the paper; T.M., V.G., E.Z., C.G.M., E.C., C.N., E.C., R.B., and G.Z. evaluated and reported the imaging findings; V.C. and R.G collected follow-up data; R.A, M.P., A.C., and W.A. drafted the manuscript; and all the authors revised and commented on the paper and approved the final version of the manuscript.

Funding Open access funding provided by Università degli Studi di Napoli Federico II within the CRUICARE Agreement.

Ethical approval All procedures performed in studies involving human participants were in accordance with the ethical standards of the institutional and/or national research committee and with the 1964 Helsinki Declaration and its later amendments or comparable ethical standards. This article does not contain any studies with animals performed by any of the authors.

Informed approval Informed consent was obtained from all individual participants included in the study.

Conflict of interest The authors declare no conflict of interest.

\section{References}


1. Wu Z, McGoogan JM. Characteristics of and Important Lessons From the Coronavirus Disease 2019 (COVID-19) Outbreak in China: Summary of a Report of 72314 Cases From the Chinese Center for Disease Control and Prevention. JAMA. 2020;323:1239-42.

2. Zaim S, Chong JH, Sankaranarayanan V, Harky A. COVID-19 and multiorgan response. Curr Probl Cardiol. 2020;45:100618.

3. Bansal M. Cardiovascular disease and COVID-19. Diabetes Metab Syndr. 2020;14:247-50.

4. Petrovic V, Radenkovic D, Radenkovic G, Djordjevic V, Banach M. Pathophysiology of cardiovascular complications in COVID-19. Front Physiol. 2020;11:575600.

5. Song P, Li W, Xie J, Hou Y, You C. Cytokine storm induced by SARS-CoV-2. Clin Chim Acta. 2020; 509280-7.

6. Nishiga M, Wang DW, Han Y, Lewis DB, Wu JC. COVID-19 and cardiovascular disease: from basic mechanisms to clinical perspectives. Nat Rev Cardiol. 2020;17:543-58.

7. Huang C, Wang Y, Li X, Ren L, Zhao J, Hu Y, et al. Clinical features of patients infected with 2019 novel coronavirus in Wuhan, China. Lancet. 2020;39:497-506.

8. The European Society for Cardiology. ESC guidance for the diagnosis and management of CV disease during the COVID-19 pandemic. https://www.escardio.org/Education/COVID-19-andCardiology/ESCCOVID-19-Guidance. (Last update: 10 June 2020).

9. Wang D, Hu B, Hu C, Zhu F, Liu X, Zhang J, et al. Clinical characteristics of 138 hospitalized patients with 2019 novel Coronavirus-infected pneumonia in Wuhan, China. JAMA. 2020;323:1061-9.

10. Peterson E, Lo KB, DeJoy R, Salacup G, Pelayo J, Bhargav R, et al. The relationship between coronary artery disease and clinical outcomes in COVID-19: a single-center retrospective analysis. Coron Artery Dis. 2021;32:367-71.

11. Santoso A, Pranata R, Wibowo A, Al-Farabi MJ, Huang I, Antariksa B. Cardiac injury is associated with mortality and critically ill pneumonia in COVID-19: A meta-analysis. Am J Emerg Med. 2021;44:352-7.

12. Verberne HJ, Acampa W, Anagnostopoulos C, Ballinger J, Bengel F, De Bondt P, et al. European Association of Nuclear Medicine (EANM). EANM procedural guidelines for radionuclide myocardial perfusion imaging with SPECT and SPECT/CT: 2015 revision. Eur J Nucl Med Mol Imaging. 2015;42:1929-40.

13. Acampa W, Di Benedetto C, Cuocolo A. An overview of radiotracers in nuclear cardiology. J Nucl Cardiol. 2000;7:701-7.

14. Esteves FP, Raggi P, Folks RD, Keidar Z, Askew JW, Rispler S, et al. Novel solid-state-detector dedicated cardiac camera for fast myocardial perfusion imaging: Multicenter comparison with standard dual detector cameras. J Nucl Cardiol. 2009;16:927-34.

15. Mannarino T, Assante R, Ricciardi C, Zampella E, Nappi C, Gaudieri V, et al. Head-to-head comparison of diagnostic accuracy of stress-only myocardial perfusion imaging with conventional and cadmium-zinc telluride single-photon emission computed tomography in women with suspected coronary artery disease. J Nucl Cardiol. 2021;28:888-97. 
16. Germano G, Kavanagh PB, Waechter P, Areeda J, Van Kriekinge S, Sharir T, et al. A new algorithm for the quantitation of myocardial perfusion SPECT. I: technical principles and reproducibility. J Nucl Med. 2000;41:712-9.

17. Nappi C, Gaudieri V, Acampa W, Assante R, Zampella E, Mainolfi CG, et al. Comparison of left ventricular shape by gated SPECT imaging in diabetic and nondiabetic patients with normal myocardial perfusion: A propensity score analysis. J Nucl Cardiol. 2018;25:394-403.

18. Zampella E, Acampa W, Assante R, Nappi C, Gaudieri V, Mainolfi CG, et al. Combined evaluation of regional coronary artery calcium and myocardial perfusion by $82 \mathrm{Rb} \mathrm{PET} / \mathrm{CT}$ in the identification of obstructive coronary artery disease. Eur J Nucl Med Mol Imaging. 2018;45:521-9.

19. Thygesen K, Alpert JS, Jaffe AS, Chaitman BR, Bax JJ, Morrow DA, et al; Executive Group on behalf of the Joint European Society of Cardiology (ESC)/American College of Cardiology (ACC)/American Heart Association (AHA)/World Heart Federation (WHF) Task Force for the Universal Definition of Myocardial Infarction. Fourth Universal Definition of Myocardial Infarction (2018). Circulation. 2018;138:e618-e651.

20. Simon R, Makuch RW. A non-parametric graphical representation of the relationship between survival and the occurrence of an event: Application to responder versus non-responder bias. Stat Med. $1984 ; 3: 35-44$.

21. Mantel N, Byar DP. Evaluation of response time data involving transient states: An illustration using heart-transplantation data. J Am Stat Assoc. 1974;69:81-6.

22. Chen N, Zhou M, Dong X, Qu J, Gong F, Han Y, et al. Epidemiological and clinical characteristics of 99 cases of 2019 novel coronavirus pneumonia in Wuhan, China: a descriptive study. Lancet. 2020;395:507e13.

23. Yang YM, Hsu CY, Lai CC, Yen MF, Wikramaratna PS, Chen HH, et al. Impact of comorbidity on fatality rate of patients with Middle East respiratory syndrome. Sci Rep. 2017;7:11307.

24. Nappi C, Megna R, Acampa W, Assante R, Zampella E, Gaudieri V, et al. Effects of the COVID-19 pandemic on myocardial perfusion imaging for ischemic heart disease. Eur J Nucl Med Mol Imaging. 2021;48:421-7.

25. Einstein AJ, Shaw LJ, Hirschfeld C, Williams MC, Villines TC, Better N, et al, INCAPS COVID Investigators Group. International impact of COVID-19 on the diagnosis of heart disease. J Am Coll Cardiol. 2021;77:173-85.

26. Hirschfeld CB, Shaw LJ, Williams MC, Lahey R, Villines TC, Dorbala S, et al.; INCAPS-COVID Investigators Group. Impact of COVID-19 on cardiovascular testing in the United States versus the rest of the world: The INCAPS-COVID Study. JACC Cardiovasc Imaging. 2021 Jun 10:S1936878X(21)00265-5. doi: 10.1016/j.jcmg.2021.03.007. Epub ahead of print. PMID: 34147434.

27. Li M, Dong Y, Wang H, Guo W, Zhou H, Zhang Z, et al. Cardiovascular disease potentially contributes to the progression and poor prognosis of COVID-19. Nutr Metab Cardiovasc Dis. 2020;30:1061-7.

28. Babapoor-Farrokhran S, Gill D, Walker J, Rasekhi RT, Bozorgnia B, Amanullah A. Myocardial injury and COVID-19: Possible mechanisms. Life Sci. 2020;253:117723. 
29. Hamming I, Timens W, Bulthuis ML, Lely AT, Navis G, van Goor H. Tissue distribution of ACE2 protein, the functional receptor for SARS coronavirus. A first step in understanding SARS pathogenesis. $J$ Pathol. 2004;203:631-7.

30. Beyerstedt S, Casaro EB, Rangel ÉB. COVID-19: angiotensin-converting enzyme 2 (ACE2) expression and tissue susceptibility to SARS-CoV-2 infection. Eur J Clin Microbiol Infect Dis. 2021;40:905-19.

31. Moccia F, Gerbino A, Lionetti V, Miragoli M, Munaron LM, Pagliaro P, et al. COVID-19-associated cardiovascular morbidity in older adults: a position paper from the Italian Society of Cardiovascular Researches. Geroscience. 2020;42:1021-49.

32. Dhakal BP, Sweitzer NK, Indik JH, Acharya D, William P. SARS-CoV-2 Infection and Cardiovascular Disease: COVID-19 Heart. Heart Lung Circ. 2020;29:973-87.

33. Bonaventura A, Vecchié A, Dagna L, Martinod K, Dixon DL, Van Tassell BW, et al. Endothelial dysfunction and immunothrombosis as key pathogenic mechanisms in COVID-19. Nat Rev Immunol. 2021;21:319-29.

\section{Figures}

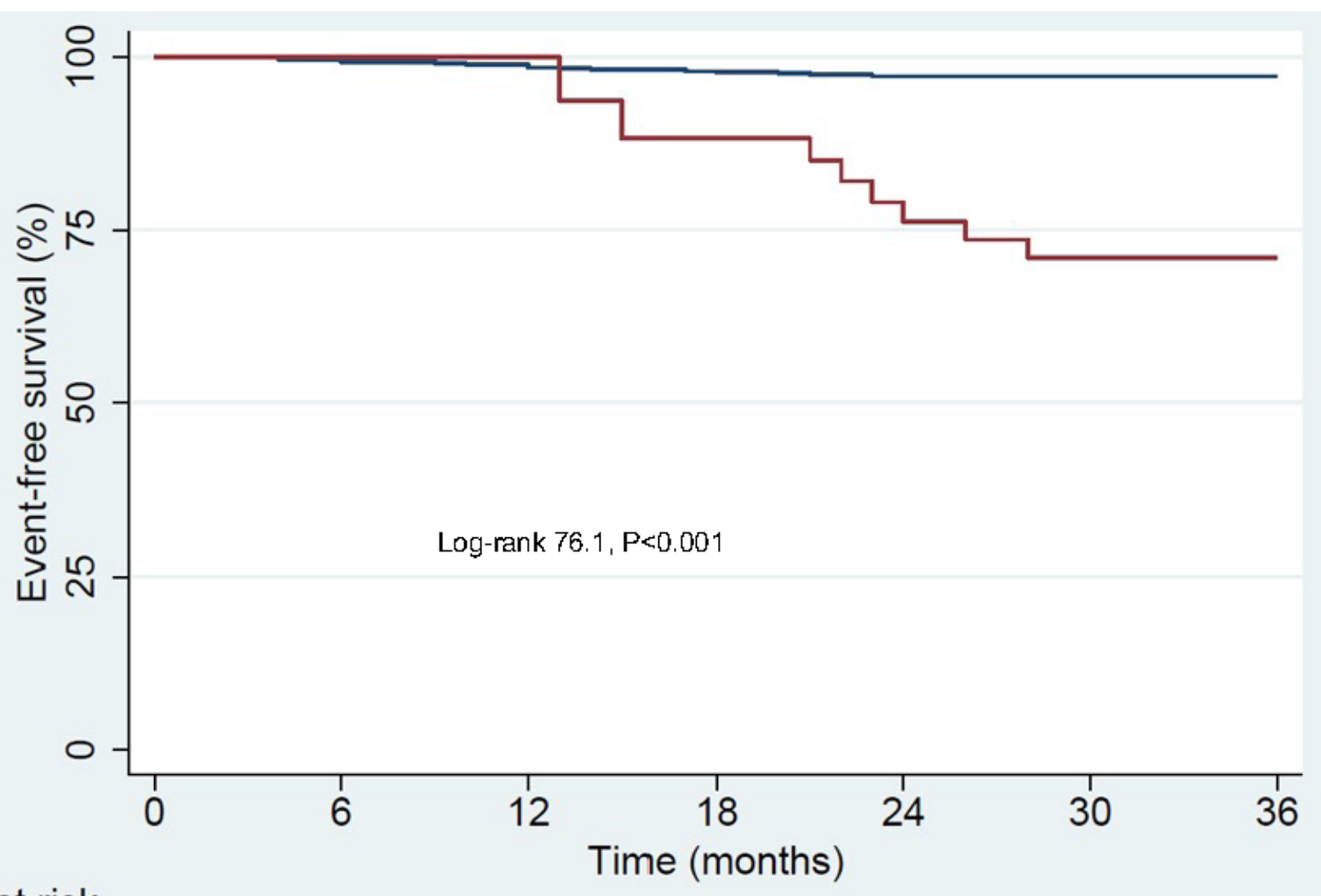

Number at risk

$\begin{array}{lcccccc}\text { Covid- } 877 & 873 & 852 & 836 & 468 & 414 & 6 \\ \text { Covid+ } 0 & 0 & 15 & 18 & 28 & 21 & 1\end{array}$


Figure 1

Simon and Makuch's modified Kaplan-Meier curves in patients with (red line) and without (blue line) COVID-19 infection (time-dependent covariate). COVID-, patients without infection; COVID+, patients with infection; MPS-, patients with normal MPS (TPD $<5 \%)$; MPS+, patients with abnormal MPS (TPD $\geq 5 \%$ )

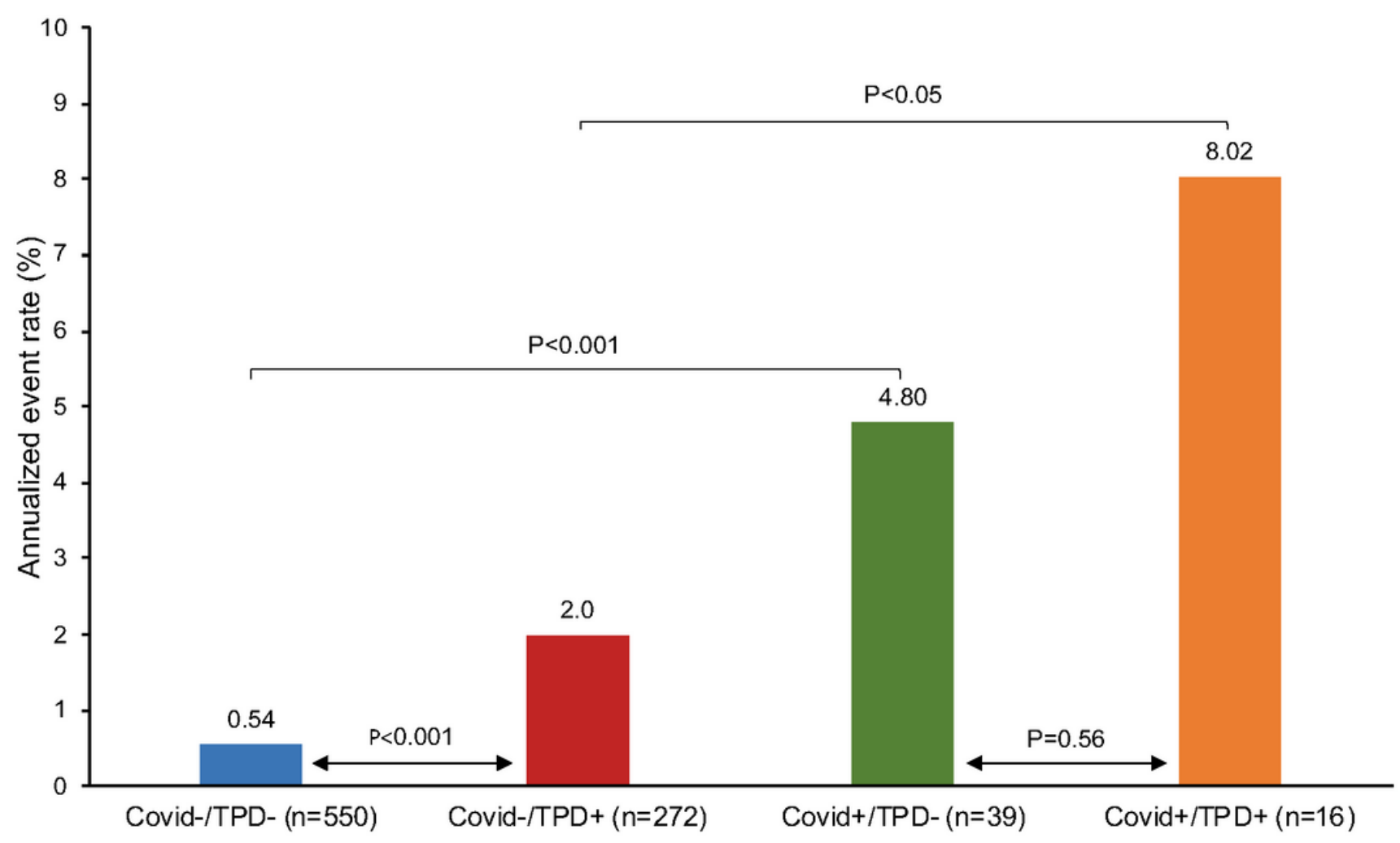

Figure 2

Annualized event rate according to COVID-19 infection and stress MPS findings. COVID-, patients without infection; COVID+, patients with infection; MPS-, patients with normal MPS (TPD <5\%); MPS+, patients with abnormal MPS (TPD $\geq 5 \%)$ 


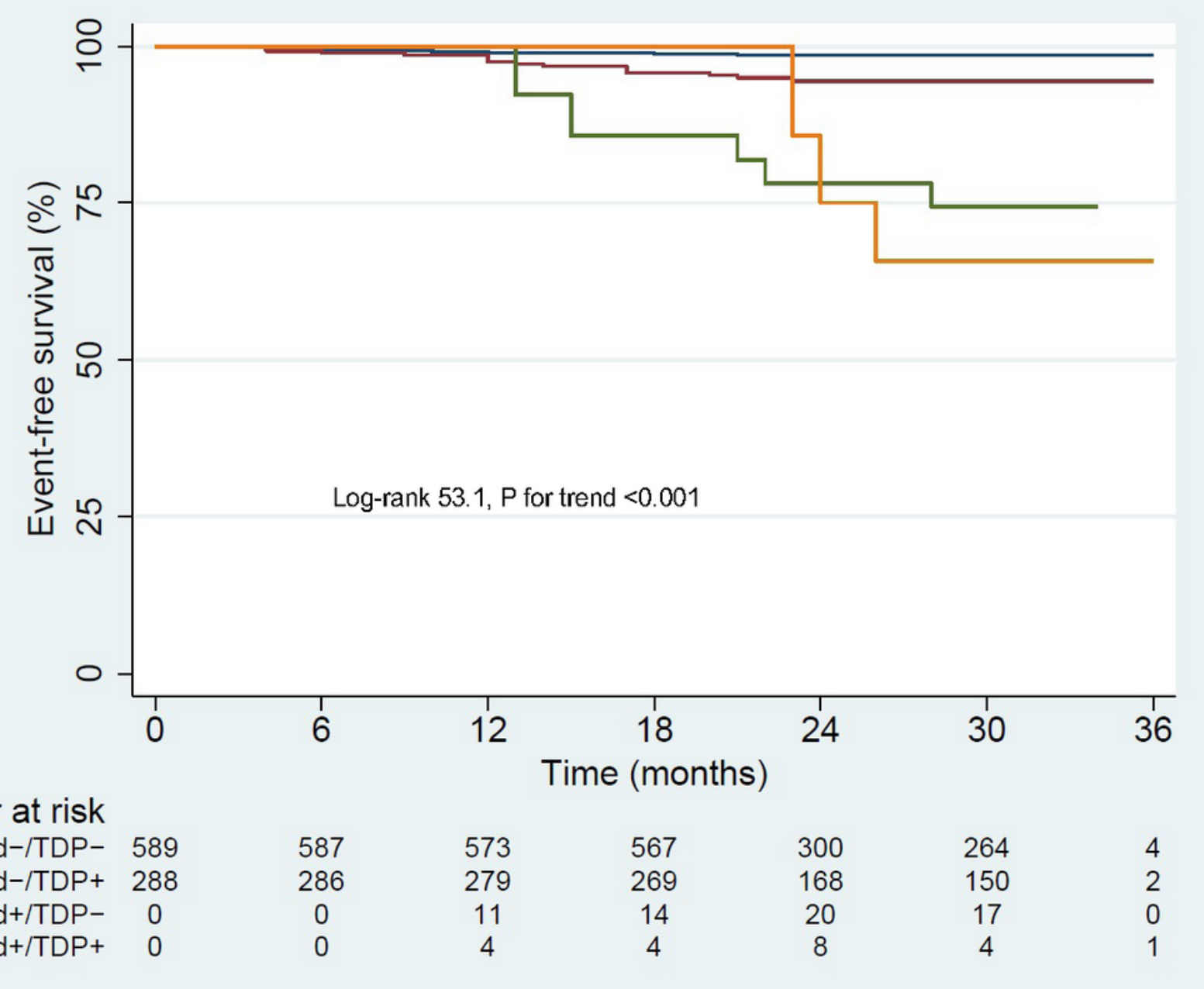

\section{Figure 3}

Simon and Makuch's modified Kaplan-Meier curves in patients without COVID-19 and normal MPS (blue line), without COVID-19 and abnormal MPS (red line), with COVID-19 and normal MPS (green line) and with COVID-19 and abnormal MPS (yellow line). COVID-, patients without infection; COVID+, patients with infection; MPS-, patients with normal MPS (TPD $<5 \%)$; MPS+, patients with abnormal MPS (TPD $\geq 5 \%$ ) 